\title{
OCCUPATIONAL STRESS AND MUSCULOSKELETAL SYMPTOMS IN FIREFIGHTERS
}

\section{ELPIDOFOROS S. SOTERIADES ${ }^{1,2}$, LILIA PSALTA $^{3}$, STAVROULA LEKA $^{4}$, and GEORGE SPANOUDIS ${ }^{3}$}

${ }^{1}$ American Medical Center, Nicosia, Cyprus

Department of Occupational Medicine

${ }^{2}$ Harvard School of Public Health, Boston, USA

Department of Environmental Health, Environmental and Occupational Medicine and Epidemiology (EOME)

${ }^{3}$ University of Cyprus, Nicosia, Cyprus

Department of Psychology

${ }^{4}$ University of Nottingham, Nottingham, UK

School of Medicine, Division of Psychiatry and Applied Psychology, Centre for Organizational Health and Development

\begin{abstract}
Objectives: The aim of this study was to evaluate the potential association between occupational stress and musculoskeletal symptoms in firefighters. Material and Methods: Data were collected among Cypriot firefighters through a battery of adapted questionnaires completed anonymously. Results: A total of 430 firefighters (a response rate of 68\%) completed the survey (the age range: 21-60 years). A total of 11\% of firefighters reported moderate to extremely severe stress through the Copenhagen Psychosocial Questionnaire and Depression, Anxiety and Stress Scale. A total of $40 \%$ of firefighters reported musculoskeletal symptoms, the most frequent being back pain. Multivariable-adjusted logistic regression models showed that occupational stress was associated with a 50\% higher risk of musculoskeletal symptoms in firefighters after adjusting for age, smoking and obesity $(\mathrm{OR}=1.52, \mathrm{p}=0.04)$. In addition, a positive dose-response relationship was found between occupational stress and musculoskeletal symptoms. Conclusions: Occupational stress constitutes a significant risk for firefighters and is associated with higher prevalence of musculoskeletal symptoms at work. Int J Occup Med Environ Health. 2019;32(3):341-52
\end{abstract}

Key words:

physical activity, questionnaire survey, work-related stress, firefighters, musculoskeletal disorders, psychosomatic stress

\section{INTRODUCTION}

Occupational or work-related stress (WRS) constitutes one of the most prevalent work-related health problems in Europe and around the world [1]. Stress that is developed or exacerbated by work is considered work-related. Occupational stress has been described as the adverse reaction experienced by workers when workplace demands and responsibilities are greater than those the worker can comfortably manage or are beyond the workers' capabilities [2]. It can affect workers in many different ways and originate from different sources. Occupational stress has been associated with exposure to different workplace hazards, including noise and temperature, work organizational and management issues, as well as workplace harass-

Funding: this research was supported by the Cyprus Research Promotion Foundation (grant No. 0308/BIE/21 entitled "Epidemiology and management of occupational stress and musculoskeletal disorders in firefighters," grant manager: George Spanoudis, Ph.D.).

Received: September 16, 2017. Accepted: August 23, 2018.

Corresponding author: Elpidoforos Soteriades, American Medical Center, Department of Occupational Medicine, 215 Spyrou Kyprianou Ave., 2047 Strovolos, Nicosia, Cyprus (e-mail: esoteria@hsph.harvard.edu). 
ment (bullying and violence) [3-6]. It can affect employees from all occupational settings and industries [7, 8].

Work-related stress is in itself considered an adverse health outcome, and has been attributed to many different physical and psychosocial hazards observed in the workplace. However, it can also represent an important risk factor for several other adverse workplace health outcomes leading to physical and mental illness [9-11]. Chronic work-related stress has been linked to the development of burnout syndrome (a state of emotional, mental, and physical fatigue caused by exorbitant and extended stress) [12,13], and may also lead to chronic anxiety and depression [14,15]. For example, in a recent study performed among Japanese firefighters, the quantity of work, the role conflict and ambiguity, inadequate support from the supervisor, shift work and low self-esteem were significantly related to depressive symptoms [4]. Occupational stress has also been associated with other physical and behavioral problems such as hypertension [16], cardiovascular disease [17], and alcohol and substance abuse [18]. It is also well documented that employee stress may negatively affect business performance since it has been associated with reduced productivity in the workplace [19].

Firefighters are exposed to many different workplace hazards that could lead to acute and/or chronic work-related stress throughout their career [20]. Particularly, firefighters' duties such as assisting, hoisting and carrying victims from accidents and/or fire scenes may be associated with extreme mental stress, especially when they involve fatalities of children and young adults [21]. Heavy physical work under extreme conditions in urban or wild land fires, extensive shift work, and poor communication with co-workers and managers (poor employee interpersonal relationships) may also be associated with a stressful work environment. In addition, separation of firefighters from their loved ones during natural or manmade catastrophes and the lack of social support may also play an important role as sources of occupational stress [22]. Surprisingly, individual and social pathways through which all these multiple work-related stressors affect firefighters' mental health over the course of their career have not been adequately studied [23].

Recently, work-related stress has been reported as a risk factor for employee musculoskeletal problems [24-29]. However, little is known regarding the potential association of occupational stress with musculoskeletal problems among firefighters [30]. The objective of the study was to evaluate occupational stress among firefighters and explore its potential association with musculoskeletal symptoms in this occupational group.

\section{MATERIAL AND METHODS}

\section{Study participants}

The present study was conducted in the Cyprus Fire Service, which constitutes the body of professional firefighters currently living and working in Cyprus. All professional firefighters from all districts (5 in total) and all regional fire stations in Cyprus (33 in total) were invited to participate in an anonymous web-based survey. Confidentiality was protected since data collection was done through a web-link, which was provided at the official website of the Cyprus Fire Service. Questionnaires were completed individually and all responses were immediately downloaded into a secure file. The survey link was available to all firefighters. The study was approved by the Cyprus National Bioethics Committee.

\section{Data collection}

Data were collected through anonymously completed questionnaires that were translated into the Greek language using the back translation method with qualified translators. This procedure involved a forward translation from the original language (English) to the intended language (Greek). Second, the intended language (Greek) was then back translated into the original language (English) and compared to the original version. Inaccuracies 
in the intended language were simply identified through differences in meaning that occurred in the backward translation.

To further prevent any inaccuracies from the original versions due to translation, the battery of assessment tools was pilot-tested in a random group of 30 firefighters. The pilot sample was randomly selected from the entire firefighter population. The aim of the pilot study was to:

- determine whether the participants understood the questions within their cultural boundaries,

- assess the feasibility of the full-scale survey that followed, and

- establish the effectiveness of the sampling frame and techniques used.

Some minor adaptation of items took place following this pilot. The questionnaires included open-ended questions, Likert scales and binary response questions.

Demographic information was collected on all study participants and included categorical age, gender, marital status, education, job position/ranking, smoking, BMI, exercise and overall health status/well being.

\section{Questionnaires}

Psychosocial working conditions, as well as health and well-being were evaluated using the Copenhagen Psychosocial Questionnaire (COPSOQ) [31]. The COPSOQ uses 19 dimensions to measure the level of psychosocial stressors at work. The different dimensions are further divided into sub-categories. Four different items are used to assess "demands," 5 items to evaluate "influence and development," 8 scales, 1 single item measuring "interpersonal support and relationship," and 1 scale is used to appraise "job insecurity." In addition, 6 outcome variables were measured on job satisfaction, an intention to leave, general health, burnout (scale: Personal Burnout), cognitive stress and satisfaction with life.

Overall, the standard version of COPSOQ consists of 87 items using a 5-point Likert scale. In essence, the features of COPSOQ show values beginning from a minimum of 0 , (which stands for the minimum indication or the least possible value), to a maximum of 100 (standing for the most probable value). In order to present translucent and understandable results, the scale value is calculated as a simple average. The low or high values are related to the indicated context of an outcome. For example, high values for "meaning of work" or "possibilities for development" designate a positive significance, whereas high values for "emotional demands" or "role conflict" designate a harmful implication.

Firefighters' depression, anxiety and stress were also assessed using the Depression, Anxiety and Stress Scale (DASS) [32]. For the purposes of the survey, the short version of the scale (DASS-21) was used, which consists of 21 items and all questions are evaluated on a Likert scale. In principle, a 4-point (ranging 0-3) severity scale measures the extent to which each state has been experienced over the past week, with 0 representing "Did not apply to me at all" and 3 "Applied to me very much, or most of the time." The DASS-21 scale is further sub-divided into 3 sub-scales, namely depression, anxiety and stress, using 7 items for each sub-category.

To assess musculoskeletal problems, the Nordic Musculoskeletal Questionnaire (NMQ) [33] was used. This scale consists of structured, multiple choice questions and all answers are in the form of a dichotomous yes/no response assessing musculoskeletal issues. The questionnaire consists of 2 parts: a general questionnaire and a more detailed body-part specific questionnaire. The questionnaire was designed to answer the question: "Do musculoskeletal troubles occur in a given population, and if so, in what parts of the body are they localized?" Specific questions then concentrated on each anatomic region.

With this consideration in mind, a questionnaire was constructed in which the human body (viewed from the back) is divided into 9 anatomical regions (neck, shoulders, upper back, elbows, wrists/hands, low back, hips/thighs, knees, an- 
kles/feet), while the questionnaire asks about the presence of physical problems including ache, pain or discomfort for the past 7 days and past 12 months in each of the body areas, respectively. To measure the severity of the functional status, it also includes a question: "Have you at any time during the last 12 months been prevented from doing your normal work (at home or away from home) because of the trouble?" This question assesses the effects of the experienced symptoms in terms of their consequence on work activities, and in association with the duration of the symptoms.

\section{Statistical analyses}

Data were imported into the SPSS 20 statistical package which was used to perform statistical analyses. Differences in the means of continuous and categorical variables were assessed using the t-test and $\chi^{2}$ test, respectively. Simple and multi-variable adjusted logistic regression models were used to assess the potential association between work-related stress and musculoskeletal symptoms. Workrelated stress was the main explanatory variable of the regression models as assessed by the COPSOQ questionnaire (dichotomized by the mean value and/or quartiles). Reported musculoskeletal symptoms (yes/no) based on the NMQ were used as the dependent variable (outcome).

\section{RESULTS}

A total of 430 firefighters (a response rate of $68 \%$ among all professional firefighters) completed the survey questionnaires (380 males [88.4\%], and 50 females [11.6\%]). Firefighters' age ranged 21-60. The following percentages, $17 \%, 29.5 \%, 26.5 \%$ and $16.3 \%$, corresponded to the $21-30,31-40,41-50$, and 51-60 age category, respectively. The majority of study participants (77\%) were firefighters, and the remaining were sergeants and senior officers. Table 1 presents the demographic characteristics of the study sample as a whole.

Table 1. Demographic characteristics of the studied firefighters $(\mathrm{N}=430)$ in Cyprus

\begin{tabular}{|c|c|c|}
\hline Variable & $\mathrm{n}$ & $\%$ \\
\hline \multicolumn{3}{|l|}{ Age } \\
\hline $21-30$ years & 76 & 17.7 \\
\hline $31-40$ years & 170 & 39.5 \\
\hline $41-50$ years & 114 & 26.5 \\
\hline $51-60$ years & 70 & 16.3 \\
\hline \multicolumn{3}{|l|}{ Gender } \\
\hline male & 380 & 88.4 \\
\hline female & 50 & 11.6 \\
\hline \multicolumn{3}{|l|}{ Marital status } \\
\hline single & 64 & 14.9 \\
\hline married & 332 & 77.2 \\
\hline divorced/separated/widowed & 32 & 7.9 \\
\hline \multicolumn{3}{|l|}{ Education } \\
\hline primary/middle school & 11 & 2.6 \\
\hline high school & 318 & 74.0 \\
\hline diploma/bachelor's degree & 85 & 19.8 \\
\hline master's degree or higher & 16 & 3.7 \\
\hline
\end{tabular}


Table 1. Demographic characteristics of the studied firefighters $(\mathrm{N}=430)$ in Cyprus - cont.

\begin{tabular}{|c|c|c|}
\hline Variable & $\mathrm{n}$ & $\%$ \\
\hline \multicolumn{3}{|l|}{ Ranking } \\
\hline firefighter & 331 & 77.0 \\
\hline sergeant & 61 & 14.2 \\
\hline chief & 27 & 6.3 \\
\hline other senior manager & 10 & 2.3 \\
\hline \multicolumn{3}{|l|}{ Smoking } \\
\hline non-smoker & 160 & 37.2 \\
\hline ex-smoker & 82 & 19.1 \\
\hline occasional smoker & 46 & 10.7 \\
\hline regular smoker & 142 & 33.0 \\
\hline \multicolumn{3}{|l|}{ Body mass index (BMI) } \\
\hline$<25$ & 168 & 39.1 \\
\hline $25<\mathrm{BMI}<30$ & 204 & 47.4 \\
\hline$\geq 30$ & 53 & 12.3 \\
\hline \multicolumn{3}{|l|}{ Physical exercise } \\
\hline never & 72 & 16.7 \\
\hline 1-2 times/week & 160 & 37.2 \\
\hline 3-4 times/week & 130 & 30.2 \\
\hline 5-6 times/week & 37 & 8.6 \\
\hline daily & 28 & 6.5 \\
\hline \multicolumn{3}{|l|}{ Health/well-being } \\
\hline excellent & 4 & 0.9 \\
\hline very good & 12 & 2.8 \\
\hline good & 117 & 27.2 \\
\hline average & 223 & 51.9 \\
\hline bad & 74 & 17.2 \\
\hline
\end{tabular}

Mean scores and standard deviations of work-related stress, based on the 2 questionnaires used in the study, are delineated in Table 2. The internal consistency estimates of the reliability of the scales used were quite high, as expressed with Cronbach's $\alpha$, which was 0.91 for the DASS stress scale, and 0.90 for the COPSOQ stress items. The correlation between the COPSOQ work-related stress items and the DASS stress sub-scale was 0.49 and was statistically significant $(p<0.001)$. Using the DASS stress scale, it was found that $83.3 \%, 5.5 \%$, $7.7 \%, 3.1 \%$ and $0.5 \%$ of the sample were categorized into the normal, mild, moderate, severe, and extremely severe sub-category of stress, respectively. It is also interesting to report that the correlation between the DASS stress subscale and the DASS depression sub-scale was 0.85 and was also statistically significant $(\mathrm{p}<0.001)$. A total of $40 \%$ of firefighters reported musculoskeletal symptoms based on the NMQ questionnaire. The most 


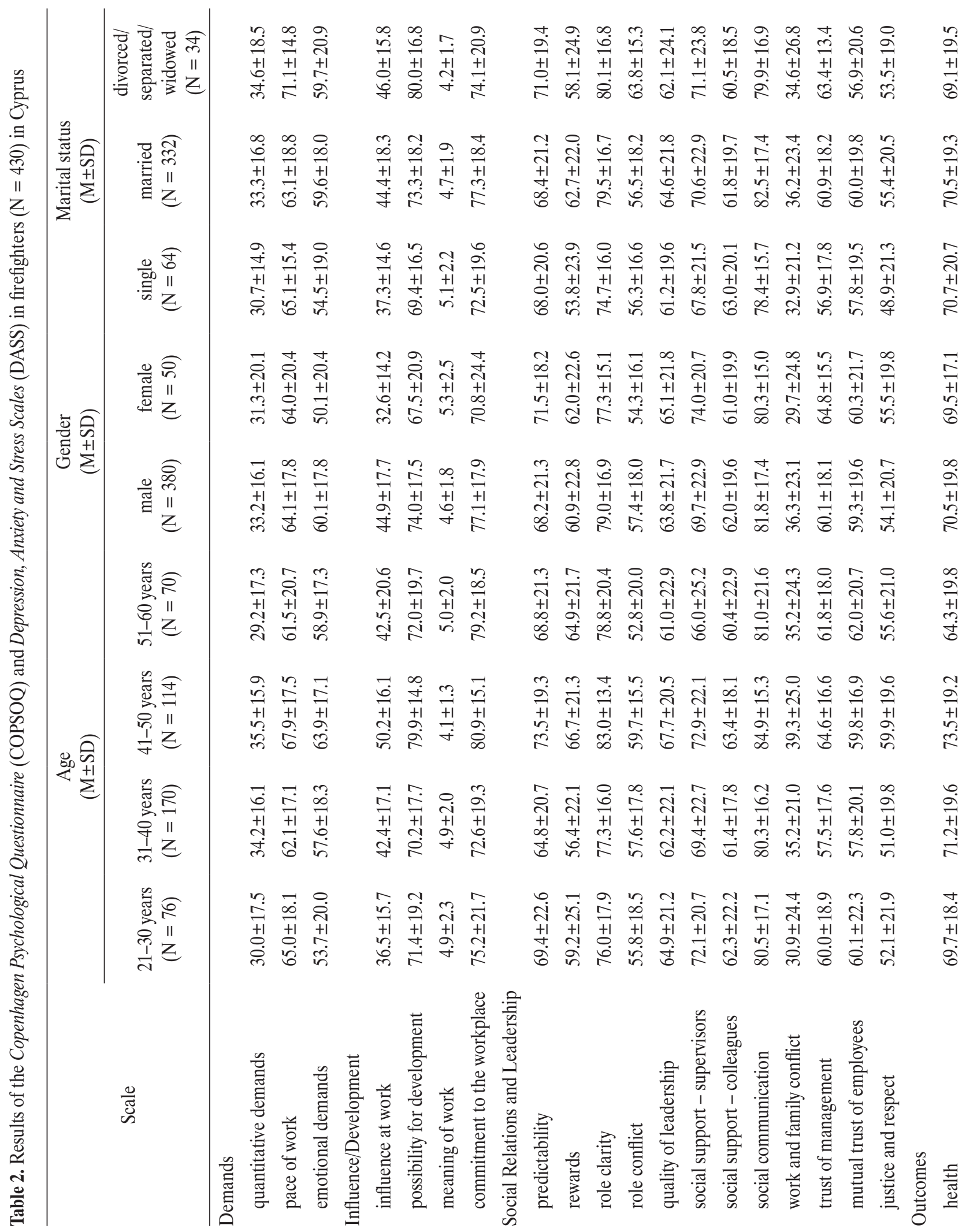



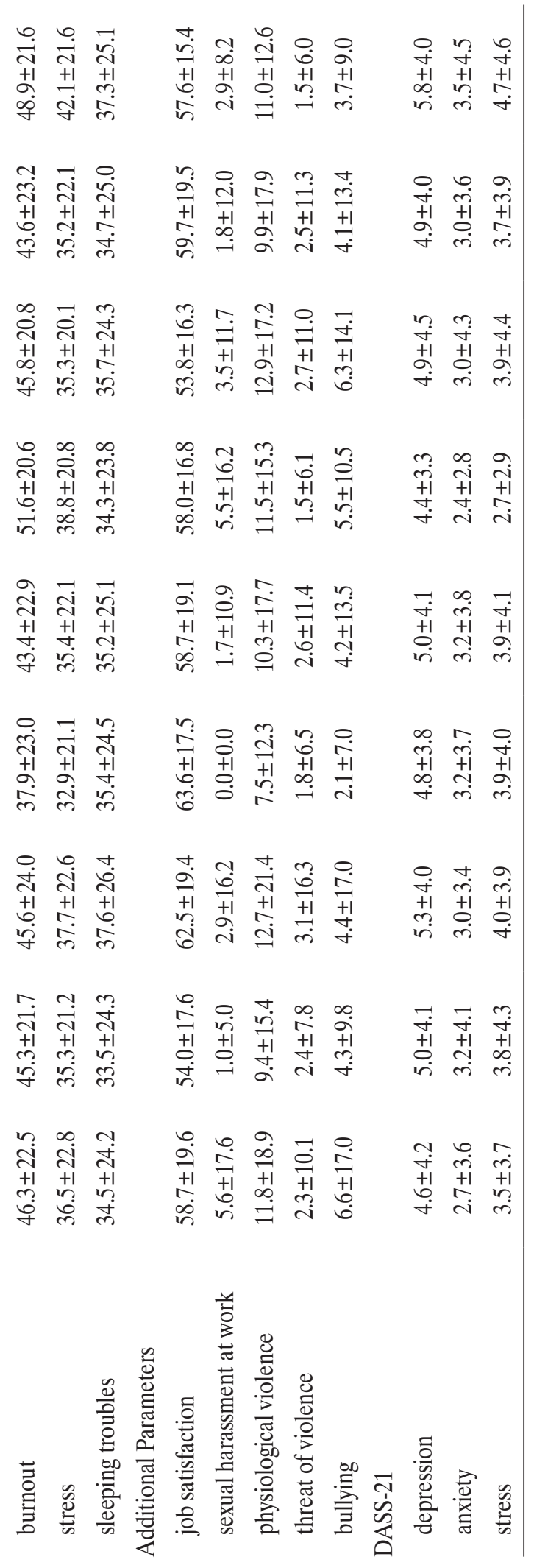

frequently reported musculoskeletal symptoms by anatomical site were back pain (26\%), shoulder pain (20.6\%), knee problems (20.1\%), neck pain (18.5\%), upper extremities (10.3\%), upper back (9.4\%), and ankles (5.5\%).

Table 3 presents the bi-variable and multi-variable adjusted regression models for the association between occupational stress and musculoskeletal symptoms in firefighters. Regression models were adjusted for age, smoking, BMI and physical exercise. Firefighters who had scores above the mean on the COPSOQ work-related stress sub-scale $(\mathrm{M}=40.05)$ had about a $50 \%$ higher risk of reporting musculoskeletal symptoms $(\mathrm{OR}=1.52, \mathrm{p}<0.05)$, even after adjusting for age, smoking and BMI. In addition, a dose-response relationship was found between workrelated stress and reported musculoskeletal symptoms. Firefighters with work-related stress above the mean (the third quartile) and those in the fourth (highest) quartile reported more musculoskeletal symptoms, compared with firefighters with scores below the mean. Firefighters in the highest quartile of work-related stress had about a 2.3 times higher risk of reporting musculoskeletal symptoms, compared to those below the mean stress score. When physical exercise was included into the multi-variable adjusted model, the association persisted and its magnitude did not practically change.

It is also interesting to report that there was a statistically significant association and a dose-response inverse relationship between physical exercise and reported musculoskeletal symptoms. Firefighters who reported physical exercise had about a 2.4 times lower risk of reporting musculoskeletal symptoms (Table 3, Model 4). In addition, compared to firefighters with sedentary lifestyle, firefighters who reported physical activity 1-2 days/week, 3-4 days/week and $\geq 5$ days/week had about a 2.5 times, 2 times and 2.7 times lower risk of reporting musculoskeletal symptoms, respectively (Table 3, Model 5). As physical exercise increased in firefighters, reported musculoskeletal symptoms decreased. 
Table 3. Logistic regression models for the association between work-related stress and musculoskeletal symptoms in firefighters $(\mathrm{N}=430)$ in Cyprus

\begin{tabular}{|c|c|c|}
\hline Model & OR $(95 \% \mathrm{CI})$ & $\mathrm{p}$ \\
\hline \multicolumn{3}{|l|}{ Model 1} \\
\hline work-related stress (score $>50 \%)^{\mathrm{a}}$ & $1.52(1.02-2.25)$ & $0.04^{*}$ \\
\hline \multicolumn{3}{|l|}{ Model 2} \\
\hline work-related stress (score $>50 \%)^{\mathrm{a}}$ & $1.52(1.02-2.27)$ & $0.04^{*}$ \\
\hline age $(>30$ years vs. $<30$ years) & $1.47(0.85-2.53)$ & 0.17 \\
\hline \multicolumn{3}{|l|}{ BMI } \\
\hline category $1(\mathrm{BMI}<25)$ & - & \\
\hline category $2(25<\mathrm{BMI}<30)$ & $1.10(0.71-1.70)$ & 0.67 \\
\hline category $3(\mathrm{BMI} \geq 30)$ & $1.31(0.69-2.47)$ & 0.41 \\
\hline smoking (smokers vs. non-smokers) & $0.96(0.64-1.43)$ & 0.83 \\
\hline \multicolumn{3}{|l|}{ Model 3} \\
\hline \multicolumn{3}{|l|}{ work-related stress ${ }^{a}$} \\
\hline below the mean & - & \\
\hline third quartile & $1.12(0.69-1.79)$ & \\
\hline fourth quartile & $2.29(1.37-3.83)$ & 0.65 \\
\hline age $(>30$ years vs. $<30$ years) & $1.50(0.87-2.60)$ & $0.002 *$ \\
\hline \multicolumn{3}{|l|}{ BMI } \\
\hline category 1 (BMI < 25) & - & 0.14 \\
\hline category $2(25<\mathrm{BMI}<30)$ & $1.10(0.71-1.71)$ & \\
\hline category $3(\mathrm{BMI} \geq 30)$ & $1.33(0.69-2.53)$ & 0.67 \\
\hline smoking (smokers vs. non-smokers) & $0.93(0.62-1.39)$ & 0.39 \\
\hline \multicolumn{3}{|l|}{ Model 4} \\
\hline work-related stress (score $>50 \%)^{\mathrm{a}}$ & $1.44(0.96-2.17)$ & $0.077^{* *}$ \\
\hline age $(>30$ years vs. $<30$ years) & $1.47(0.85-2.56)$ & 0.16 \\
\hline \multicolumn{3}{|l|}{ BMI } \\
\hline category 1 (BMI < 25) & - & \\
\hline category $2(25<\mathrm{BMI}<30)$ & $1.10(0.71-1.72)$ & 0.66 \\
\hline category $3(\mathrm{BMI} \geq 30)$ & $1.23(0.64-2.35)$ & 0.54 \\
\hline smoking (smokers vs. non-smokers) & $0.90(0.60-1.36)$ & 0.63 \\
\hline exercise (physical activity vs. sedentary) & $0.42(0.25-0.72)$ & $0.002 *$ \\
\hline \multicolumn{3}{|l|}{ Model 5} \\
\hline work-related stress $(\text { score }>50 \%)^{\mathrm{a}}$ & $1.56(1.02-2.38)$ & $0.039^{*}$ \\
\hline age (> 30 years vs. $<30$ years) & $1.35(0.77-2.37)$ & 0.30 \\
\hline \multicolumn{3}{|l|}{ BMI } \\
\hline category 1 (BMI < 25) & - & \\
\hline category $2(25<\mathrm{BMI}<30)$ & $1.23(0.77-1.95)$ & 0.39 \\
\hline category $3(\mathrm{BMI} \geq 30)$ & $1.28(0.66-2.49)$ & 0.46 \\
\hline
\end{tabular}


Table 3. Logistic regression models for the association between work-related stress and musculoskeletal symptoms in firefighters $(\mathrm{N}=430)$ in Cyprus - cont.

\begin{tabular}{llc}
\hline \multicolumn{1}{c}{ Model } & OR $(95 \% \mathrm{CI})$ & $\mathrm{p}$ \\
\hline $\begin{array}{l}\text { Model } 5 \text { - cont. } \\
\text { smoking (smokers vs. non-smokers) }\end{array}$ & $0.88(0.58-1.35)$ & 0.56 \\
exercise & & \\
no physical activity & $0.40(0.23-0.73)$ & $0.003^{*}$ \\
1-2 days/week & $0.52(0.28-0.96)$ & $0.036^{*}$ \\
3-4 days/week & $0.37(0.15-0.90)$ & $0.029^{*}$ \\
$\geq 5$ days/week
\end{tabular}

${ }^{a}$ Work-related stress was assessed based on the COPSOQ stress sub-scale.

$* \mathrm{p}<0.05 ; * \mathrm{p}<0.10$.

\section{DISCUSSION}

To the best of the authors' knowledge, this is the first study in Cyprus to assess work-related stress among firefighters. It is also one of very few studies in the international literature to evaluate the association between occupational stress and musculoskeletal symptoms among firefighters. It was found that about 1 in 10 firefighters reported significant work-related stress using 2 different internationally standardized scales, which were statistically significantly correlated. In addition, the authors found that a high percentage of firefighters $(40 \%)$ reported musculoskeletal symptoms, the most frequently reported ones including back pain, shoulder pain and knee problems. Finally, a statistically significant association was identified between occupational stress and reported musculoskeletal symptoms among firefighters, even after adjusting for several other explanatory factors. The above association also exhibited a positive dose-response relationship.

Firefighters who scored above the mean level in the COPSOQ stress sub-scale had about a 50\% higher risk of reporting musculoskeletal symptoms, compared to those firefighters with stress scores lower than the mean. In addition, it was found in a dose-response relationship model that firefighters in the third and fourth quartiles of the COPSOQ stress sub-scale scores had about a 1.1 and
2.3 times higher risk of reporting musculoskeletal symptoms, compared to firefighters with scores below the mean, respectively.

The study findings are supported by other scientific reports associating work-related stress and musculoskeletal problems [24-29]. They are also consistent with a similar study performed among South Korean firefighters in which the authors reported statistically significant associations between the sub-scales of work-related stress and musculoskeletal symptoms [30]. In another study, higher perceived psychological job demands as well as job insecurity were associated with lower back musculoskeletal disorders among long-haul international female flight attendants [27]. In this study, firefighters in the highest quartile of work-related stress had about a 2.3 times higher risk of reporting musculoskeletal symptoms. It is also important to note that, along with the association of work-related stress, physical exercise was found to be statistically significantly associated with reported musculoskeletal symptoms in firefighters, showing an inverse relationship which is in agreement with a wealth of scientific literature [34].

Limitations of this study include the relatively small number of participants and the cross-sectional study design limiting the authors' ability to explore causal relationships. However, the response rate achieved was high, consider- 
ing the national firefighter population in Cyprus targeted by the study. The supportive evidence regarding the association between work-related stress and musculoskeletal symptoms requires further longitudinal research to explore the possible underlying causal relationships that may contribute to these findings.

\section{CONCLUSIONS}

The authors documented a relatively high percentage of firefighters reporting work-related stress and a much higher percentage of firefighters who also reported musculoskeletal symptoms. In addition, a statistically significant positive association was found between occupational stress and musculoskeletal symptoms, even after adjusting for several other explanatory variables. These results require further investigation using a prospective study design, in order to verify the above findings and explore the potential causal relationships. The research may prove helpful in informing the development of appropriate workplace policies for disease prevention and health promotion programs, for both mental health and musculoskeletal problems in the workplace, not only among firefighters but also in other occupational groups.

\section{ACKNOWLEDGMENTS}

The authors would like to acknowledge the cooperation and contribution of the Cyprus Fire Service.

\section{REFERENCES}

1. Brookes K, Limbert C, Deacy C, O'Reilly A, Scott S, Thirlaway K. Systematic review: Work-related stress and the HSE management standards. Occup Med (Lond). 2013;63(7):46372, https://doi.org/10.1093/occmed/kqt078.

2. Leka S, Kortum E. A European framework to address psychosocial hazards. J Occup Health. 2008;50(3):294-6, https:// doi.org/10.1539/joh.M6004.

3. Salazar MK, Beaton R. Ecological model of occupational stress. Application to urban firefighters. AAOHN J. 2000;48(10):470-9.
4. Saijo Y, Ueno T, Hashimoto Y. Twenty-four-hour shift work, depressive symptoms, and job dissatisfaction among Japanese firefighters. Am J Ind Med. 2008;51(5):380-91, https:// doi.org/10.1002/ajim.20571.

5. Son SY, Lee JY, Tochihara Y. Occupational stress and strain in relation to personal protective equipment of Japanese firefighters assessed by a questionnaire. Ind Health. 2013;51(2):214-22, https://doi.org/10.2486/indhealth. 2012-0075.

6. Brown J, Mulhern G, Joseph S. Incident-related stressors, locus of control, coping, and psychological distress among firefighters in Northern Ireland. J Trauma Stress. 2002; 15(2):161-8, https://doi.org/10.1023/A:1014816309959.

7. Acquadro Maran D, Varetto A, Zedda M, Ieraci V. Occupational stress, anxiety and coping strategies in police officers. Occup Med (Lond). 2015;65(6):466-73.

8. Clegg A. Occupational stress in nursing: A review of the literature. J Nurs Manag. 2001;9(2):101-6, https://doi.org/ 10.1046/j.1365-2834.2001.00216.x.

9. Nistor K, Nistor A, Ádám S, Szabó A, Konkolÿ Thege B, Stauder A. [The relationship of work-related psychosocial risk factors with depressive symptoms among Hungarian workers: Preliminary results of the Hungarian Work Stress Survey]. Orv Hetil. 2015;156(11):439-48, https://doi.org/ 10.1556/OH.2015.30103. Hungarian.

10. Bethge M. [Patients with low back pain. Psychosocial workrelated factors and return to work - A literature review]. Orthopade. 2010;39(9):866-73. German.

11. Lalić H, Bukmir L, Ferhatović M. Examining psychic consequences in firefighters exposed to stress. Coll Antropol. 2007;31(2):451-5.

12. Mikołajewska E. [Work-related stress and burnout in physiotherapists - A literature review]. Med Pr. 2014;65(5):693701, https://doi.org/10.13075/mp.5893.00078. Polish.

13. Ângelo RP, Chambel MJ. The reciprocal relationship between work characteristics and employee burnout and engagement: A longitudinal study of firefighters. Stress Health. 2015;31(2):106-14, https://doi.org/10.1002/smi.2532. 
14. Honda A, Date Y, Abe Y, Aoyagi K, Honda S. Work-related stress, caregiver role, and depressive symptoms among Japanese workers. Saf Health Work. 2014;5(1):7-12, https://doi. org/10.1016/j.shaw.2013.11.002.

15. Saijo Y, Ueno T, Hashimoto Y. Job stress and depressive symptoms among Japanese fire fighters. Am J Ind Med. 2007;50(6):470-80, https://doi.org/10.1002/ajim.20460.

16. Babu GR, Jotheeswaran AT, Mahapatra T, Mahapatra S, Kumar A Sr, Detels R, et al. Is hypertension associated with job strain? A meta-analysis of observational studies. Occup Environ Med. 2014;71(3):220-7, http://oem.bmj.com/content/ 71/3/220.long.

17. Krajnak KM. Potential contribution of work-related psychosocial stress to the development of cardiovascular disease and type II diabetes: A brief review. Environ Health Insights. 2014;8(Suppl 1):41-5.

18. Hosoda T, Osaki Y, Okamoto H, Wada T, Otani S, Mu H, et al. Evaluation of relationships among occupational stress, alcohol dependence and other factors in male personnel in a Japanese local fire fighting organization. Yonago Acta Med. 2012;55(3):63-8.

19. Cocker F, Martin A, Scott J, Venn A, Sanderson K. Psychological distress, related work attendance, and productivity loss in small-to-medium enterprise owner/managers. Int J Environ Res Public Health. 2013;10(10):5062-82, https:// doi.org/10.3390/ijerph10105062.

20. Chung IS, Lee MY, Jung SW, Nam CW. Minnesota multiphasic personality inventory as related factor for post traumatic stress disorder symptoms according to job stress level in experienced firefighters: 5-year study. Ann Occup Environ Med. 2015;27:16, https://doi.org/10.1186/s40557-015-0067-y.

21. De Soir E, Knarren M, Zech E, Mylle J, Kleber R, van der Hart O. A phenomenological analysis of disaster-related experiences in fire and emergency medical services personnel. Prehosp Disaster Med. 2012;27(2):115-22, https://doi. org/10.1017/S1049023X12000507.

22. Carpenter GS, Carpenter TP, Kimbrel NA, Flynn EJ, Pennington ML, Cammarata C, et al. Social support, stress, and suicidal ideation in professional firefighters. Am J Health Behav. 2015;39(2):191-6, https://doi.org/10.5993/AJHB.39.2.5.

23. Bongers PM, Ijmker S, van den Heuvel S, Blatter BM. Epidemiology of work related neck and upper limb problems: Psychosocial and personal risk factors (part I) and effective interventions from a bio behavioural perspective (part II). J Occup Rehabil. 2006;16(3):279-302, https://doi. org/10.1007/s10926-006-9044-1.

24. Huang GD, Feuerstein M, Sauter SL. Occupational stress and work-related upper extremity disorders: Concepts and models. Am J Ind Med. 2002;41(5):298-314, https://doi. org/10.1002/ajim.10045.

25. Kopec JA, Sayre EC. Work-related psychosocial factors and chronic pain: A prospective cohort study in Canadian workers. J Occup Environ Med. 2004;46(12):1263-71.

26. Dick RB, Lowe BD, Lu ML, Krieg EF. Further trends in work-related musculoskeletal disorders: A comparison of risk factors for symptoms using quality of work life data from the 2002, 2006, and 2010 General Social Survey. J Occup Environ Med. 2015;57(8):910-28, https://doi.org/10.1097/ JOM.0000000000000501.

27. Lee H, Wilbur J, Kim MJ, Miller AM. Psychosocial risk factors for work-related musculoskeletal disorders of the lowerback among long-haul international female flight attendants. J Adv Nurs. 2008;61(5):492-502, https://doi.org/10.1111/ j.1365-2648.2007.04511.x.

28. Widanarko B, Legg S, Devereux J, Stevenson M. Interaction between physical and psychosocial risk factors on the presence of neck/shoulder symptoms and its consequences. Ergonomics. 2015;58(9):1507-18, https://doi.org/10.1080/00 140139.2015.1019936.

29. Widanarko B, Legg S, Devereux J, Stevenson M. The combined effect of physical, psychosocial/organisational and/or environmental risk factors on the presence of work-related musculoskeletal symptoms and its consequences. Appl Ergon. 2014;45(6): 1610-21, https://doi.org/10.1016/j.apergo.2014.05.018.

30. Kim MG, Kim KS, Ryoo JH, Yoo SW. Relationship between occupational stress and work-related musculoskeletal 
disorders in Korean male firefighters. Ann Occup Environ Med. 2013;25(1):9, https://doi.org/10.1186/2052-4374-25-9.

31. Kristensen, TS, Hannerz H, Hogh A, Borg V. The Copenhagen Psychosocial Questionnaire. A tool for the assessment and improvement of the psychosocial work environment. Scand J Work Environ Health. 2005;31(6):438-89, https:// doi.org/10.5271/sjweh.948.

32. Crawford JR, Henry JD. The Depression Anxiety Stress Scales (DASS): Normative data and latent structure in a large non-clinical sample. Br J Clin Psychol. 2003;42(Pt 2): 111-31, https://doi.org/10.1348/014466503321903544.
33. Kuorinka I, Jonsson B, Kilbom A, Vinterberg H, BieringSørensen F, Andersson G, et al. Standardised Nordic questionnaires for the analysis of musculoskeletal symptoms. Appl Ergon. 1987;18(3):233-7, https://doi.org/10.1016/00036870(87)90010-X.

34. Rodríguez-Romero B, Martínez-Rodríguez A, Pita-Fernández S, Riveiro-Temprano S, Carballo L. Efficacy of a multimodal therapeutic exercise program in shellfish gatherers for the prevention of musculoskeletal disorders: A quasiexperimental study. J Sports Med Phys Fitness. 2011;51(4): $616-24$.

This work is available in Open Access model and licensed under a Creative Commons Attribution-NonCommercial 3.0 Poland License - http://creativecommons.org/ licenses/by-nc/3.0/pl/deed.en. 